\title{
Sociogênese possível dos saraus: uma história de rupturas na cultura brasileira
}

\author{
Sociogenesis of the saraus: a history of disruptions in \\ Brazilian culture
}

\section{Sociogenesis posible de los saraus: una historia de rupturas en la cultura brasilera}

\author{
iD) Lucas Amaral de Oliveira \\ Universidade Federal da Bahia, Salvador, Bahia, Brasil \\ lucasoliveira.ufba@gmail.com
}

Resumo: A partir de um resgate histórico-cultural, este artigo discute uma sociogênese possível do termo e da prática dos saraus literários em São Paulo, instâncias que funcionam, hoje, como catalisadores de vivências artísticas nas periferias brasileiras. Partindo de duas "narrativas de origem", dos poetas Binho e Sérgio Vaz - pioneiros do movimento da literatura marginal no contexto paulistano -, retomo a ideia e parte da história desse tipo de atividade nos salões europeus, verificando como ocorreu a sua transposição para a rotina artística nacional, processo que esteve intermediado por mecenas e membros da elite cafeeira. Esses salões/saraus fomentaram um dos mais relevantes movimentos da história cultural do Brasil: o modernismo paulista. Meu argumento é que houve uma correlação entre o apogeu de salões artísticos na cidade de São Paulo, entre o fim do século XIX e o início do XX, a prosperidade de palacetes de uma burguesia agrário-industrial interessada nos benefícios da vida urbana, a eclosão de vanguardas no campo artístico nacional e o ciclo de industrialização por que passava o estado de São Paulo. Nesse contexto, os saraus acabaram constituindo espaços capazes de fundir a absorção de novas ideias oriundas da Europa com a defesa das 
artes nacionais, processo que ratificou desejos de mudanças no campo artístico e social da época.

Palavras-chave: Saraus. Literatura Marginal. Sociogênese. Modernismo. São Paulo.

Abstract: From a cultural and historical review, the aim of this essay is to propose a feasible sociogenesis of the term and practice of the saraus ("open mic literary events"), which operate today as important spaces for literary encounters and experiences in the urban peripheries. Starting from the "narratives of origin" constructed by poets Binho and Sérgio Vaz, pioneers of the so-called Marginal Literature Movement in São Paulo, I return to the history of this artistic activity in the European salons and to its transposition into the Brazilian cultural routine. This process was sponsored by artistic patrons, and subsidized by members of newly wealthy coffee elite, which has fostered one of the largest artistic movements in Brazil: the modernism. My argument is that there was a correlation among the heyday of the art salons/saraus in São Paulo, between the late nineteenth and early twentieth, the prosperity of palaces in the city center by an expanding agrarian-industrial bourgeoisie, the outbreak of avant-garde in the artistic field, and the circle of industrialization the state of São Paulo was going through. These salons ended up creating spaces capable of merging the absorption of new ideas coming from Europe with the intense reiteration of a "national culture", a process that ratified some desires for cultural and social changes.

Keywords: Saraus. Marginal Literature. Sociogenesis. Modernism. São Paulo.

Resumen: Desde un rescate histórico-cultural, analizo una sociogénesis posible del término y de la práctica de los saraus literarios, instancias que funcionan hoy como importantes catalizadores de encuentros y experiencias artísticas en las periferias brasileñas. A partir de las "narrativas de origen" de los poetas Binho y Sérgio Vaz, pioneros del Movimiento de la Literatura Marginal en el contexto de São Paulo, vuelvo a la idea y parte de la historia de este tipo de actividad en los salones europeos, 
verificando cómo sucedió su transposición a la rutina artística nacional, proceso mediado por mecenas y miembros de la élite cafetera. Esos saraus fomentaron uno de los movimientos más grandes en la historia cultural de Brasil: el modernismo. Mi argumento es que hubo una correlación entre el apogeo de las salas de arte en la ciudad de São Paulo, entre fines del siglo XIX y principios del siglo XX, la prosperidad de los palacios de una burguesía agrario-industrial interesada en las ventajas de la vida urbana, el estallido de vanguardias en el campo artístico nacional y el ciclo de industrialización del estado de São Paulo. Esos salones literarios resultaron ser espacios provocadores capaces de fusionar la absorción de nuevas ideas procedentes de Europa con la reiteración de las artes nacionales, un proceso que ratificó los deseos de cambios en el campo artístico y social.

Palabras clave: Saraus. Literatura Marginal. Sociogénesis. Modernismo. São Paulo.

Data de recebimento do artigo: 04/04/2020

Data de aprovação do artigo: 03/07/2020 
Sociogênese possível dos saraus: uma história de rupturas na cultura brasileira Lucas Amaral de Oliveira

\section{Introdução}

No início dos anos 2000, a prática dos saraus literários, que, em outra época, funcionaram como importantes núcleos de convivência artística e social entre setores mais abastados das elites urbanas, foi retomada e ressignificada nas periferias de grandes cidades brasileiras.

Pesquisas sobre experiências literárias em periferias urbanas, a partir de uma perspectiva das ciências sociais, têm levantado hipóteses instigantes sobre a eclosão contemporânea dos saraus na história da cultura brasileira, argumentando que a redefinição atual dessa prática nas periferias tem sido crucial para a consolidação do movimento da literatura marginal no Brasil (BALBINO, 2016; BERTELLI \& FELTRAN, 2017; CLEMENTE \& SILVA, 2014; COSTA, 2011; DOMINGOS, 2015; GUNUTZMANN, 2017; LEITE, 2014; NASCIMENTO, 2009, 2011; OLIVEIRA, 2018a; 2018b; PARDUE \& OLIVEIRA, 2018; REYES, 2013; SALOM, 2014; TENNINA, 2017). Contudo, quando se desloca o prisma analítico e metodológico para as "narrativas de origem", que têm sido erigidas pelos/as agentes do movimento, especialmente no contexto paulistano, notam-se explicações complementares - e nem por isso menos sugestivas -, que indicam outras chaves de interpretação. Gostaria de partir de duas dessas narrativas que me parecem congêneres: a de Binho (Robinson de Oliveira Padial), responsável pelo Sarau do Binho, no Campo Limpo; e a de Sérgio Vaz, à frente da Cooperifa, um dos saraus periféricos precursores na capital paulista e que mais lograram sucesso na cena contemporânea.

Ambos os autores, buscando uma "unidade originária" a partir de explicações históricas para uma possível gênese sociocultural dos saraus, remontam a vinda da corte portuguesa ao Rio de Janeiro, em 1808, chegando à organização de requintados salões que serviram de base para a consagração de uma vanguarda modernista em São Paulo, no início do século XX. Não pretendo analisar as duas instâncias de produção, circulação e consumo de 
Sociogênese possível dos saraus: uma história de rupturas na cultura brasileira Lucas Amaral de Oliveira

objetos literários. Ao levar essas narrativas a sério, pretendo, de um lado, conferir sua factualidade, de maneira a revisitar parte da história cultural do país a partir de uma leitura a contrapelo; de outro, contribuir para o debate acerca de procedimentos usados ao longo da história para negligenciar espaço e reconhecimento às produções que fugiam da economia do gosto de certa elite urbana.

Tomando ambos os enunciados como provocações sociológicas e ignições reflexivas, empreendo uma digressão histórica, a fim de aludir a uma possível ascendência do termo "sarau". O objetivo é flagrar os primórdios dos salões literários do país enquanto espólio de um estilo de vida europeu, a partir da análise de momentos-chaves da história cultural paulista, sobretudo dos anos que antecederam o modernismo - movimento que deu início, segundo Silviano Santiago (1989), a uma "tradição de ruptura" nas letras nacionais. Esforço-me para relacionar tais práticas com um contexto social, político, econômico e artístico mais amplo, responsável por acomodar manifestações estéticas disruptivas. $O$ objetivo é propor uma sociogênese possível do termo e da prática dos saraus, que hoje têm se vertido em um catalisador importante de vivências literárias entre classes populares no Brasil inteiro. Examinar a sociogênese de uma prática implica perceber, como ensinou Norbert Elias (1994), as variações ocorridas ao longo de sua história, assim como lógicas responsáveis por fazer de um fato social contingente um fenômeno mais estruturado, de dimensões e abrangência mais extensas. Partindo das narrativas de origem enunciadas por Vaz e Binho, bem como da noção de "sociogênese", de Elias, desloco a perspectiva de análise de modo a examinar os saraus como decorrências de uma série de dinâmicas e figurações artísticas da história cultural do país.

\section{Ignição reflexiva: duas "narrativas de origem"}

Em uma das primeiras conversas que travei com Binho, durante a 40 Feira do Livro de Buenos Aires, em abril de 2014, quando 
Sociogênese possível dos saraus: uma história de rupturas na cultura brasileira Lucas Amaral de Oliveira

questionado sobre uma provável origem dos saraus, o poeta do Campo Limpo comentou que a palavra "sarau", na verdade, "teria sido um gesto de assimilação cultural de certa elite nacional letrada, de procedência ibérica, do substantivo serao, que, durante muito tempo, em países europeus, distinguiu reuniões sociais, políticas e artísticas organizadas ao entardecer", cujo intuito era "jogar conversa fora, cantar, beber, fazer amizades e constituir redes de sociabilidade". "Nós nos apropriamos da apropriação", brincou Binho.

Todavia, para ele, os saraus de hoje têm pouco ou nada a ver com o que "costumavam ser as tertúlias de outrora", justamente porque agem de outra maneira, como "tribos urbano-periféricas" que praticam "a tolerância com o outro; e acho que essa é a principal característica do sarau: conviver com um cara que você não conviveria fora dali; mas a partir dali você começa a entender o outro, a conhecer o mundo do outro" (BINHO apud HAPKE et al., 2015, p. 315).

De fato, não se trata de um termo cuja origem seja recente, tampouco sua prática muito precisa em termos históricogeográficos. Para Lucía Tennina (2013; 2017), que corrobora a hipótese do poeta Binho, a palavra "sarau", etimologicamente, teria derivado do latim serum, que significa, ao pé da letra, "final da tarde", vale dizer, período no qual esse tipo de encontro artístico costumava acontecer, geralmente em luxuosos casarões de personalidades notórias da alta sociedade, em salões e clubes exclusivistas, bem como em casas de conhecidos livreiros.

A pesquisadora argentina diz haver, na história cultural brasileira, canções, romances, cartas, crônicas e memórias que datam de meados do século XIX, e que, de forma direta, mencionam os salões justamente porque se tratava de algo ordinário na dinâmica de sociabilidade de uma burguesia em gestação. Tais atividades corriam em paralelo à distribuição de capitais simbólicos necessários para legitimar obras de arte e novos artistas "diante dos representantes da sociedade aristocrática e da intelectualidade 
Sociogênese possível dos saraus: uma história de rupturas na cultura brasileira Lucas Amaral de Oliveira

da época. E, ao mesmo tempo, havia também um interesse de exibição da posição de classe" (TENNINA, 2017, p. 114).

Sérgio Vaz (2008), em sua autobiografia - que também apresenta a história de formação da Cooperifa -, elaborou uma narrativa de origem também interessante para explicar o "retorno" dos saraus. Há aspectos que poderiam ser explorados no longo excerto do poeta; por ora, quero que o/a leitor/a leve em conta o que o poeta articulou acerca da escolha do termo:

No Brasil, entre o fim do século XIX e no início do século XX, o sarau era o evento mais elegante da sociedade [...]. Esses eventos eram chamados de "salões" - muito provavelmente pelo ambiente que ocupavam. Chegaram como tradição importada da Família Real, em 1808, e imediatamente ganharam terreno no Rio de Janeiro. Era o local onde se reunia a Corte, e onde também deveriam acontecer os encontros para regar o cérebro da aristocracia e dos nativos que sonhavam ganhar um certo "ar europeu". São Paulo só entrou no circuito mais tarde, quando perdeu os ares provincianos e seus ricos fazendeiros de café começaram a fazer de tudo para afrancesarem-se. [...] A partir dos anos 1940, a dinâmica da "elite culta" mudou e os ricos saraus foram escasseando. A organização desse tipo de evento mudou de mãos e coube aos intelectuais universitários realizálos [...]. Sem saber de nada disso, eu e o Pezão, numa fria noite de outubro de 2001, criamos na senzala moderna chamada periferia o Sarau da Cooperifa [...] (VAZ, 2008, p. 89-90).

Trata-se, para além de uma hipótese virtualmente factível sobre os primórdios da prática no país, de uma narrativa histórica que complementa a leitura que o poeta Binho improvisou em nossa conversa, na medida em que supõe uma apropriação disruptiva, nos termos de Santiago (1989) - ou então a reinvenção antropofágica -, de certa tradição cultural do país. 
Sociogênese possível dos saraus: uma história de rupturas na cultura brasileira Lucas Amaral de Oliveira

No entanto, as narrativas de origem nunca são tão simples, lineares e evolutivas quanto parecem à primeira vista; quando examinadas de perto, com minúcia, mostram-se complexas, híbridas e atravessadas por vetores e matizes históricos que devem ser ponderados na análise sociológica. Tendo em vista as narrativas de Binho e Vaz, nas próximas seções deste ensaio analiso alguns indícios literários e historiográficos sobre a história dos salões literários, dando a ver os itinerários sinuosos tomados pelo termo e pela prática até que fossem incluídos no léxico e no repertório cultural de certos setores das classes mais abastadas do Brasil.

\section{Elites que mimetizam tradições importadas}

Figura 1. Sarau, de Columbano Pinheiro

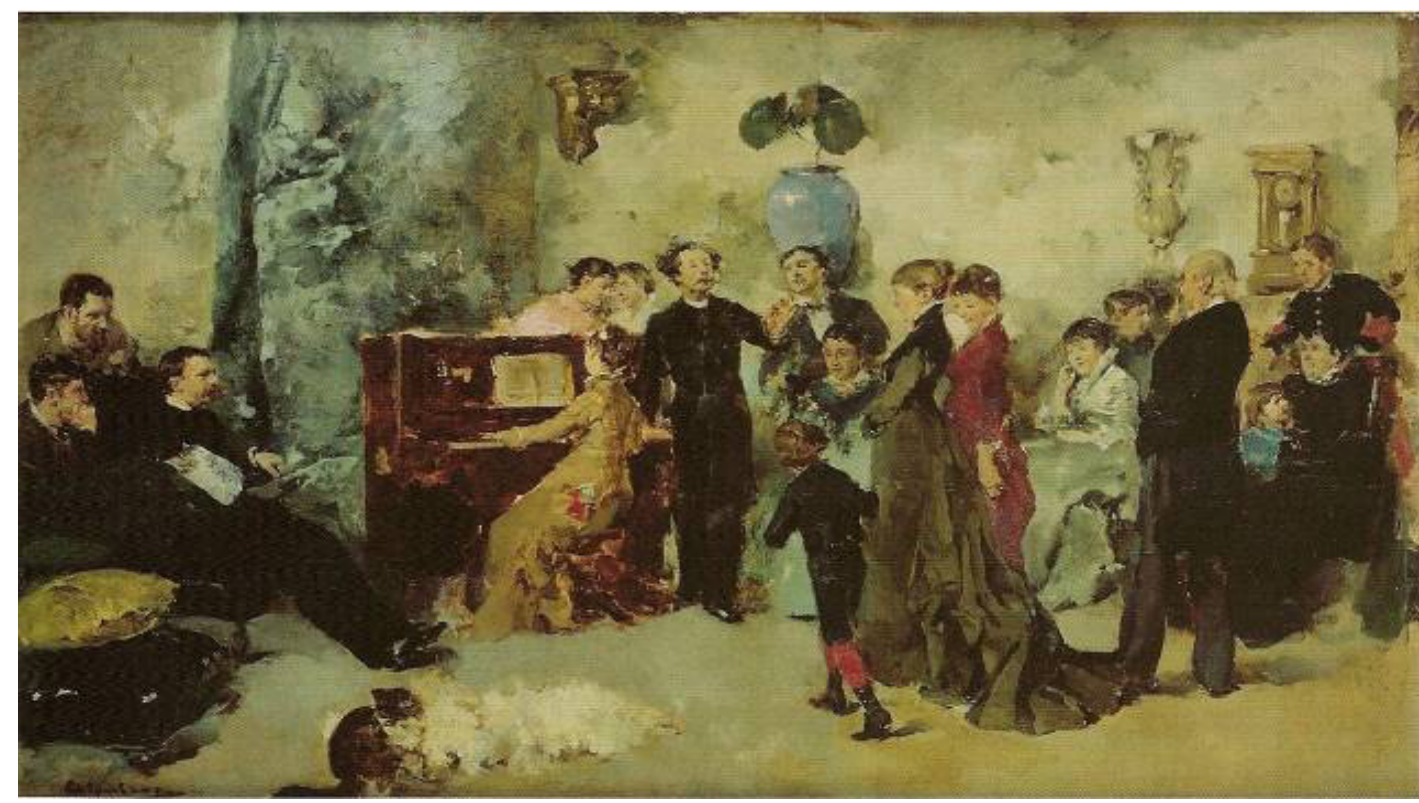

Fonte: Domínio público, coleção de João P. Coutinho (1880).

Começo com duas cenas. A primeira delas é uma obra do artista plástico Columbano Bordalo Pinheiro (1857-1929), pintor realista português, cuja formação inicia-se na Academia de Belas- 
Sociogênese possível dos saraus: uma história de rupturas na cultura brasileira Lucas Amaral de Oliveira

Artes de Lisboa em meados da década de 1870, onde foi aluno de Simões de Almeida - célebre escultor romântico -, desembocando em um período com bolsa de estudos em Paris - de 1881 a 1883, mais especificamente -, financiado pelo rei consorte $d$. Fernando II de Portugal. Foi ali que Columbano recebeu a influência de artistas como Manet e Degas, o que o ajudou a expor no prestigiado Salão de Paris, a "capital do século XIX". De volta a Lisboa, o pintor expôs um de seus mais célebres quadros, "Sarau" (de 1880), dedicado à elite lusitana.

No quadro, observa-se um piano com uma jovem a tocá-lo. De pé, muitos/as assistem atentos/as ao prelúdio, sendo que um homem, o único inteiramente virado de frente para a audiência, parece cantar ou declamar algo, dirigindo-se àqueles/as atentos/ as espectadores/as com solene seriedade. Em cada um dos cantos da cena, veem-se mulheres, homens e crianças em trajes de gala. Há rigor nas roupas. Por exemplo, o senhor, à direita, usa fraque; o menino, ao centro e de costas para o/a espectador/a, veste calções que destacam suas meias. No fundo, veem-se decorações - relógio, vaso de plantas, candeeiro. No canto esquerdo, há três sujeitos cujos semblantes e os papéis nas mãos sugerem ser intelectuais, políticos, poetas. Enfim, tudo indica que estamos diante de um retrato típico de um salão distintivo, composto provavelmente por uma classe mais abastada que monopolizava os espaços de fala, os debates políticos e a arte em geral daquela época, expressões maiores de diferenciação intelectual de uma sociedade.

Chegando ao Brasil, pode-se remeter a história dos saraus - devido ao seu formato, à nomenclatura usada, aos efeitos de sociabilidade gerados, à valorização do objeto literário e por instituírem-se enquanto instâncias relevantes de consagração interna de determinada produção simbólica - aos salões literários que serviam de palco para animadas tertúlias de setores da elite intelectual e econômica brasileira, desde a segunda metade do século XIX até os anos 1930 do século XX. Esses eventos artísticos foram retratados diversas vezes como hábitos de alta cultura em obras de escritores renomados, tais como Machado de Assis 
Sociogênese possível dos saraus: uma história de rupturas na cultura brasileira Lucas Amaral de Oliveira

(Helena, 1876), Manuel Antônio de Almeida (Memórias de um Sargento de Milícias, de 1853), José de Alencar (Senhora, de 1874) e Joaquim Manuel de Macedo (A Moreninha, 1844). Jander Sá de Araújo (2012), em um interessante texto sobre o sarau oitocentista no romantismo brasileiro, argumenta que se tratava, no limite, de reuniões sociais que exerciam um papel fundamental em relação ao lazer de elites urbanas que, por esse meio, explicitavam uma economia importada do gosto, costumes distintivos de classe, ao mesmo tempo em que apresentavam seus/suas filhos/as à "sociedade", cultivavam novas amizades e consolidavam negócios em um ambiente restrito, materializando interesses e relações das mais diversas.

Isso me leva à segunda cena que gostaria de trazer para a discussão. Tome-se um dos consagrados autores citados, Joaquim Manuel de Macedo (1820-1882), escritor fluminense, formado em medicina no Rio de Janeiro, e que, juntamente com José de Alencar (1829-1877), Manuel Antônio de Almeida (1930-1961) e outros, foi expoente do Romantismo no Brasil, vivendo da consagração dos salões cariocas. Trata-se de um trecho do capítulo XVI, intitulado "O Sarau", de uma de suas obras mais conhecidas, $A$ Moreninha, lançada em 1844, ou seja, algumas décadas antes do quadro de Columbano Bordalo Pinheiro.

Em um sarau todo o mundo tem o que fazer. O diplomata ajusta, com um copo de champanha na mão, seus intrincados negócios; todos murmuram e não há quem deixe de ser murmurado. O velho lembra-se dos minuetes e das cantigas do seu tempo, e o moço goza todos os regalos da sua época; as moças são no sarau como as estrelas no céu; estão no seu elemento: aqui uma, cantando suave cavatina, eleva-se vaidosa nas asas dos aplausos, por entre os quais surde, às vezes, um bravíssimo inopinado, que solta de lá da sala do jogo o parceiro que acaba de ganhar sua partida no écarté, mesmo na ocasião em que a moça se espicha completamente, desafinando um sustenido; daí a pouco vão outras, pelos braços de seus pares, 
Sociogênese possível dos saraus: uma história de rupturas na cultura brasileira Lucas Amaral de Oliveira

se deslizando pela sala e marchando em seu passeio, mais a compasso que qualquer de nossos batalhões da Guarda Nacional [...]. Ali vê-se um ataviado dandy que dirige mil finezas a uma senhora idosa, tendo os olhos pregados na sinhá, que se senta ao lado. Finalmente, no sarau não é essencial ter cabeça nem boca, porque para alguns é regra, durante ele, pensar pelos pés e falar pelos olhos. $\mathrm{E}$ o mais é que nós estamos num sarau. Inúmeros batéis conduziram da Corte para a ilha de... senhoras e senhores, recomendáveis por caráter e qualidades; alegre, numerosa e escolhida sociedade enche a grande casa, que brilha e mostra em toda a parte borbulhar o prazer e o bom gosto (MACEDO, 2002, p. 93).

O excerto descreve algo próximo a um recital, episódio cultural peculiar dos salões que ocorriam em palacetes de pessoas ricas do século XIX, na capital do império e, depois, em São Paulo. Esses eventos foram se tornando insígnias de uma nova classe social, objetificando elementos de diferenciação da sociedade oitocentista que, segundo Gilberto Freyre (2003), elevavam a poesia à arte do "bom gosto" de setores da elite letrada1 - que tentavam reproduzir costumes da nobreza europeia. Segundo a crítica de Roberto Schwarz, tal tipo de reunião social, conhecida como soirées, tertúlias, saraus, a depender da localidade de sua realização, era bem comum em salões da oligarquia parisiense. 0 modelo foi importado para o Brasil mediante um desses processos esquizofrênicos de "macaqueação", resquício colonial em que elites nacionais mimetizam, no âmbito artístico, as tradições do "velho mundo"; trata-se de "adotar, citar, macaquear, saquear, devorar os modos e as modas todas de forma que elas refletissem, na sua falha, a espécie de torcicolo cultural em que nos encontramos" (SCHWARZ, 2009, p.76-77).

\footnotetext{
1 Por "elite letrada" entendo grupos que, vivendo em um novo contexto urbano, viam-se como depositários de uma tradição intelectual herdada da Europa e adaptada no Brasil. Por exemplo, em 1872, foi divulgado o resultado do primeiro censo, ocorrido nas 20 províncias do país. Encomendado por d. Pedro II, o “Recenseamento da População do Imperio do Brazil” (no original) - realizado 16 anos antes da Abolição -, segundo a Diretoria Geral de Estatística, mostra que 19\% da população livre sabia ler e escrever ( $23 \%$ entre os homens, $13 \%$ entre as mulheres). A população escravizada (e indígena) foi ignorada na pesquisa. Cf.: goo.gl/q9fKgp. Acesso: 25/01/2018.
} 
Sociogênese possível dos saraus: uma história de rupturas na cultura brasileira Lucas Amaral de Oliveira

Antonio Candido, no texto "De cortiço a cortiço", quando fala da vida intelectual brasileira no final do século XIX, explica como a configuração frouxa do nosso "nacionalismo elitista" fez com que a ideia de "cultura" oscilasse sempre entre o ufanismo em relação ao que é próprio do país e uma admiração incondicional e subserviente pelo Norte (sobretudo, França), supostamente à frente em termos de sofisticação e bom gosto. Mas, mesmo em face de tal ambiguidade, havia sempre um perigoso medo de ser brasileiro, o que levava membros de classes abastadas, setores da elite política e cultural, a falar francês em encontros sociais, a copiar as cartolas inglesas, a imitar o estilo acadêmico espetaculoso português, a admirar a disciplina alemã e a lamentar que não houvesse aqui o pragmatismo americano. Ambivalências tais que fizeram do nosso patriotismo um tipo "de amor-desprezo, uma nostalgia dos países-matrizes e uma adoração confusa da mão que pune e explora" (CANDIDO, 1993, p. 123).

Há alguns indícios historiográficos que sugerem que os "salões" literários nasceram na corte francesa do século XVII, imprimindo outro significado às palavras sala e salotto, de origem italiana (DUFOUR-MAïTRE, 2008; MARCHAL, 2001; PINHO, 2004). Tratavase de encontros nas salas de visitas da aristocracia parisiense - de regra organizados por mulheres -, ávida em atrair poetas e artistas mediante o atrativo do mecenato (DANDREY, 1996), que centralizava as atividades culturais da época com financiamentos. Esses salões, que depois seriam admirados e frequentados por membros da elite brasileira que circulavam pela Europa, funcionaram como "templos do bom-gosto" no século XVII e XVIII (LILTI, 2002). Como lembra Bourdieu (1992, p. 100), os salões podem ser lidos, complementarmente, como saldos da dissolução da corte e da própria arte cortesã, o que fez com que parte da aristocracia francesa compactuasse com certa intelligentsia burguesa e liberal em ascensão, visando à autopreservação dos costumes, e passasse a adotar alguns de seus modelos intelectuais e de suas concepções artísticas. 
Sociogênese possível dos saraus: uma história de rupturas na cultura brasileira Lucas Amaral de Oliveira

Dominique Maingueneau, em $O$ contexto da obra literária (1995), lembra que os salões do século XVII e XVIII, em Paris, eram comandados por orgulhosos salonnières que exerciam, além do papel de anfitriões, mediadores e mecenas, uma função judicativa quanto ao valor estético das obras que eram apresentadas naqueles eventos em primeira audição (COUTINHO, 2004). Ali, era possível discutir estética, mas também política; encontrar colegas e estabelecer novas conexões; manter-se a par das atualidades literárias, mas, ao mesmo tempo, reproduzir convenções e tradições artísticas em voga (MAINGUENEAU, 1995, p. 32). Os salões franceses, nessa medida, operavam como componentes essenciais de uma dinâmica artística que distribuía prestígio e consagração entre artistas cuja proposta estética caía no gosto da aristocracia.

Dan Hofstadter (1997, p. 79) lembra, nesse contexto, dos importantes salões da Princesa Matilde Bonaparte (1829-1904), ex-noiva de seu primo, Carlos Luís Napoleão Bonaparte (18081873), futuro Napoleão III, e o da Imperatriz Eugênia de Montijo (1826-1920), esposa de Napoleão III, que organizaram tertúlias que eram frequentadas por escritores do calibre de Gustave Flaubert (1821-1880). Esses salões acabaram por se mostrar, anos depois, essenciais para a autonomização do campo literário francês, tal como descrito por Bourdieu (1996).

Mas não poderíamos esquecer de outros eventos que também foram importantes para a autonomização desse campo literário entre o século XVIII e XIX, sobretudo no contexto parisiense, arranjados por Madame Juliette Récamier (1777-1849), à frente de um consagrado salão literário em uma Paris pré-revolucionária e napoleônica, e pela romancista e ensaísta Madame de Staël (17661817), uma das primeiras filósofas políticas e tida como "mãe espiritual da Europa moderna". Ambas exerceram papel crucial na difusão de uma cultura modernizante em plena efervescência revolucionária francesa, abrindo suas mansões para "livrespensadores" e liberais em política, servindo como espaços de propagação de alguns ideários da Revolução. 
Sociogênese possível dos saraus: uma história de rupturas na cultura brasileira Lucas Amaral de Oliveira

Apesar de fazer sentido as narrativas de Binho e Sérgio Vaz, sobretudo no que tange à datação do aparecimento do termo "sarau" e do fenômeno dos salões literários na vida cultural brasileira no início do século XIX - com a vinda, em 1808, da Família Real para o Rio de Janeiro -, outros fatores também se fizeram presentes na prática dos salões de pessoas influentes do país. Além da vinda da corte lusitana, também é preciso pensar no papel que uma certa "globalização precoce" cumpriu, digamos assim, no mundo letrado nacional em termos de circulação de ideias, pessoas, bens e costumes. Pelo menos é essa a hipótese de uma pesquisa coletiva subsidiada pela Fundação de Amparo à Pesquisa do Estado de São Paulo (FAPESP), "A circulação transatlântica dos impressos: a globalização da cultura no século XIX"2, que mostrou que a imprensa brasileira do século XIX já nasceu com uma determinada "disposição internacionalizante", muito tempo antes do fenômeno da globalização entrar em voga.

Já havia, em muitos países do mundo, inclusive no Brasil, uma intensa circulação de ideias, livros e folhetins, bem como de integrantes das elites econômica e culturais, o que dava ares de modernidade a países que se pensavam atrasados em termos de comércio e intercâmbio de bens materiais e simbólicos. A França, celeiro cultural de Madame Juliette Récamier e Madame de Staël na primeira metade do século XIX, possuía um mercado crescente de bens simbólicos, o que permitia ao país exportar toneladas de livros e revistas para o mundo inteiro. Aliás, parte do material era impresso em outros idiomas antes de ser exportado. No Brasil, esse material tardava apenas um mês para chegar às mãos de membros da elite letrada, após ter sido lançado na Europa, sendo que, aqui, encontrava uma legião de tradutores, editores e livreiros dispostos a fazer tais produtos circularem. Nesse sentido, deve-

2 Trata-se de um Projeto Temático (n. 11/07342-9) com vigência de 1 de setembro de 2011 a 31 de agosto de 2016, coordenado por Márcia Azevedo de Abreu, do Instituto de Estudos da Linguagem da Unicamp, e pelo historiador francês Jean Yves-Mollier, da Universidade de Versalhes-Saint-Quentin. Um episódio de circulação internacional de ideias, ainda que de modo anônimo, foi a obra Marília de Dirceu, do poeta pré-romântico Tomás Antônio Gonzaga (1744-1810), precursor do processo que conduziu à separação do Brasil de Portugal. Em razão de sua participação na Inconfidência Mineira (em 1789), Gonzaga foi acusado de insurreição, detido, preso e deportado para Moçambique. Sem que o inconfidente tomasse conhecimento, seu livro foi publicado em Lisboa, em 1792, com grande sucesso de público. Isso acarretou mais três edições da obra em Portugal, até 1800 , além de uma série de republicações no Brasil, uma tradução, em 1825, na França, sob o título Marilie: chants élégiaques de Gonzaga, seguida de traduções em outras línguas (do italiano ao latim). O curioso dessa história é que ninguém sabe quem levou a obra do poeta para fora do Brasil, ou quem foi responsável por sua circulação internacional, pois Gonzaga achava-se na costa índica da África, de onde não voltaria jamais. Cf.: goo.gl/c3GqXn. Acesso: 26/01/2018. 
Sociogênese possível dos saraus: uma história de rupturas na cultura brasileira Lucas Amaral de Oliveira

se levar em conta que foi no decorrer do século XIX, mediante as sucessivas viagens de uma pequena, porém influente, elite intelectual nacional para a Europa, além da circulação internacional de ideias e bens - a ocorrer em função do florescimento tardio da imprensa e do jornalismo no país -, que o termo "sarau" passou a ser inserido no léxico cultural de certos setores das classes mais abastadas do Brasil.

Da mesma forma, parece ter sido somente entre o final do século XIX e o início do XX que a prática entrou, de fato, em vigor no modo de vida, na economia do gosto e no glossário artístico de membros da elite, sobretudo paulista, a partir daquele processo de transposição de determinadas tradições culturais do velho mundo, tal como equacionada por Schwarz (2009). Com "elite paulista", remeto, mais designadamente, a um novo e pequeno agrupamento social que emergia, na época, no estado de São Paulo: os chamados "barões do café" ou "aristocracia cafeeira". Essa elite esteve presente, sobretudo, na mesorregião do Vale do Paraíba. São Paulo vivia, no período, seu primeiro grande ciclo de urbanização e modernização, incentivado por poderosas personalidades da indústria cafeeira, já em seu apogeu, que começavam a se estabelecer nos grandes centros urbanos e ali adquirir terrenos e casarões, a fim de usufruir de benefícios e regalias do industrialismo. Esse grupo, que enviava filhos/as para serem educados/as na Europa, reproduzindo comportamentos de beletristas, passou a superestimar e a amparar a produção e difusão artísticas. Essa disposição fez com que muitos/as se aproximassem do universo político, de projetos intelectuais e de propostas modernizantes para o mundo das artes.

\section{Mecenas, aristocracia cafeeira e modernistas}

Por volta do último quarto do século XIX, já era possível observar uma efervescência cultural com imaginações renovadoras e disruptivas em torno de alguns salões artísticos da 
Sociogênese possível dos saraus: uma história de rupturas na cultura brasileira Lucas Amaral de Oliveira

aristocracia cafeeira de São Paulo. O caso da mecena Veridiana Valéria da Silva Prado (1825-1910) é marcante nesse contexto ${ }^{3}$. Ela foi uma das mulheres mais ricas e influentes de sua época, aristocrata, proprietária de terras, financiadora e promotora da intelectualidade nacional. Dona Veridiana marcou a vida cultural paulistana na virada do século. Filha de uma das famílias mais ricas e tradicionais da elite agrário-industrial paulista, formada por barões, cafeicultores e comerciantes de açúcar, foi casada com seu tio, Martinho da Silva Prado (1843-1906), político, empresário e, também ele, próspero cafeicultor, catorze anos mais velho que a adolescente. O matrimônio ${ }^{4}$, contraído, em 1838, quando ela tinha apenas 13 anos, durou até meados de 1877, quando, então, o casal separou-se definitivamente e Veridiana, já notória, mudou-se de sua propriedade, na Rua da Consolação, para um vasto terreno entre os bairros de Santa Cecília e Higienópolis. O terreno, que ocupava uma área que abarcava desde a atual Rua Dona Veridiana até a Avenida Angélica, serviu para a construção de um de seus mais importantes palacetes.

A construção, finalizada por volta de 1884, foi denominada, posteriormente, de Chácara Vila Maria (que, desde 2008, abriga o late Clube Santos, no início da Avenida Higienópolis), e passou a cultivar um respeitável salão literário e científico, impondo, já no final do século XIX, um estilo arejado, moderno e cosmopolita a uma cidade que ainda se mostrava bastante provinciana em termos socioculturais e de costumes. O salão, que cumpriu função relevante em setores mais intelectualizados da sociedade paulistana, foi frequentado por intelectuais, artistas, cientistas e políticos de renome, como Luís Pereira Barreto, Cesário Motta Júnior, Capistrano de Abreu, José do Patrocínio, Graça Aranha, a Princesa Isabel e, inclusive, d. Pedro II, em sua última visita à cidade (HOMEM, 1996, p. 99). Segundo as pesquisas de Waldman

\footnotetext{
3 Para atentar para a centralidade que as mulheres cultas ocupavam nesse tipo de atividade cultural, vale lembrar que, no Rio de Janeiro, no mesmo período, ocorriam os famosos salões de Laurinda Santos Lobo (1878-1946), só para citar um dos mais conhecidos da então capital do império, por onde passaram nomes como Heitor Villa Lobos e Isadora Duncan. Os saraus literários e musicais ocorriam em seu requintado palacete em Santa Teresa, um dos bairros prediletos da aristocracia carioca da época. Sobre isso, cf. as pesquisas de Matta (2003) e Neves (2011).

40 casal teve seis filhos, entre eles António Prado, primeiro prefeito de São Paulo, e Eduardo Prado, um dos fundadores da Academia Brasileira de Letras; eram avós de Paulo Prado e bisavós do historiador Caio Prado Jr.
} 
Sociogênese possível dos saraus: uma história de rupturas na cultura brasileira Lucas Amaral de Oliveira

(2014) e D'Avila (2004), outras personalidades, como Joaquim Nabuco e Barão do Rio Branco, quando vinham de visita à cidade, eram sempre convidados de honra das soirées de Dona Veridiana, que, com maestria, orquestrava um dos saraus culturais mais respeitáveis e animados da segunda metade do século XIX, verdadeiras instituições sociais no sentido de promoção de atividades de difusão cultural e de intercâmbio entre intelectuais brasileiros e estrangeiros.

Segundo os estudos de Basílio e Moreira (2014) e Silva (2004), um outro precursor desse tipo de manifestação artística na capital paulista, no início do século XX, foi José de Freitas Valle (1870-1958) - mais conhecido como Senador Freitas Valle -, que abriu as portas de sua famosa Villa Kyrial (antiga Vila Gerda), localizada no atual bairro da Vila Mariana, para encontros regados à música, vinhos e discussões sobre arte, literatura, política e história - inspirando-se na moda dos grandes "salões europeus", como os de Gertrud Stein e Natalie Clifford Barney, por exemplo. O mecenas Freitas Valle - que foi, em toda sua versatilidade ocupacional, professor de francês, senador da república, poeta simbolista, mecenas, advogado, perfumista e maitre gourmet - fez de sua residência, com fachada para a Rua Domingos de Moraes, número 10, e fundos para a Rua Cubatão, no final da Avenida Paulista, um "autêntico núcleo irradiador da cultura paulistana nas duas primeiras décadas do século XX" (SALIBA, 2001, p. 306). Por seu salão, como no de Dona Veridiana, também passaram figuras ilustres da história das artes nacionais e do pensamento social brasileiro, como Lasar Segall, Guilherme de Almeida, Mário de Andrade, Anita Malfatti, Oswald de Andrade, Manuel Bandeira, Tarsila do Amaral, bem como os mecenas Paulo Prado e Olívia Guedes Penteado, entre outros/as.

Márcia Camargos (2000) ressalta que, a partir de 1912, o "senhor da Villa Kyrial", no intento de fomentar as artes paulistas, foi o responsável por encaminhar muitos/as desses/as artistas para aprimoramentos na Europa, encabeçando o famoso Pensionato Artístico do Estado de São Paulo (1912-1931), cujos recursos financeiros, a despeito de serem públicos, dependiam 
Sociogênese possível dos saraus: uma história de rupturas na cultura brasileira Lucas Amaral de Oliveira

de práticas privadas, do personalismo, de reputações de pessoas como Freitas Valle no universo das relações (SILVA, 2004; TENNINA, 2013). O benefício do Pensionato estava voltado à promoção do desenvolvimento da produção artística no Estado, uma vez que São Paulo não possuía nenhum instituto de ensino superior na área das artes. Os contemplados recebiam uma bolsa de estudos na Europa, de cinco anos; em troca, enviavam obras, esboços, partituras, programas de concertos, manuscritos literários e reportagens que ratificassem o aproveitamento da bolsa. O decreto que criou o Pensionato Artístico previu uma comissão responsável por julgar candidatos/as merecedores/as (onde constavam nomes do mecenato paulista, como o de Olívia Penteado); todavia, quem parecia decidir sobre as bolsas era, mesmo, José de Freitas Valle, em virtude de sua forte influência na política estadual (CAMARGOS, 2000, p. 159).

Foi por meio de programas como esse que viajaram para Paris e Roma nomes que viriam a ser centrais na constituição de um novo movimento cultural e de uma nova vanguarda em gestação, o modernismo: Leonor Aguiar, Victor Brecheret, Lazar Segall, Francisco Mignone, João de Souza Lima, Manoel Bandeira, Tarsila do Amaral, Heitor Villa-Lobos, Anita Malfatti e outros/as. Mas a atuação de Freitas Valle, especialmente em seu salão na Villa Kyrial, que perdurou até 1924, e com o Pensionato Artístico, encerrado por Getúlio Vargas, em 1931, assim como Dona Veridiana, é só mais um exemplo de articulador/a e realizador/a de festas, reuniões, recitais e eventos voltados à poesia, um dos tipos ideais de gatekeepers 5 , mediadores/as essenciais das trocas simbólicas da época (BOURDIEU, 2002; CASANOVA, 2002; JADHAV, 2013).

Outro exemplo seriam os saraus planejados no casarão do também mecenas e escritor Paulo Prado (1869-1943), neto de Veridiana, no início de 1920, em um palacete na Avenida

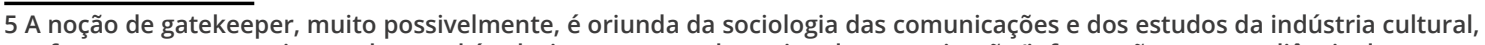
e refere-se a agentes cujo papel central é selecionar e controlar o tipo de comunicação/informação que a audiência deve receber. Nesse sentido, uma das funções do/a gatekeeper é a de gerar oportunidades culturais e influenciar a maneira como o/a artista é visto/a pelo público e como a sua obra será transmitida, recebida e valorada. Assim, ele/a desponta como mediador/a responsável por abrir portas, janelas e alçar caminhos, por criar oportunidades para o surgimento e a consagração de autores/ as. Geralmente, seu poder é maior do que a autoridade formal concedida por agentes de certo agrupamento social. Para uma síntese da discussão, cf.: Jadhav (2013). 
Sociogênese possível dos saraus: uma história de rupturas na cultura brasileira Lucas Amaral de Oliveira

Higienópolis, número 31, entre os bairros de Higienópolis e Santa Cecília, ao lado do antigo casarão onde eram realizados os salões de sua avó. O salão de Paulo Prado - autor do importante Retrato do Brasil: ensaio sobre a tristeza brasileira, de 1928 - foi, também, palco de encontros e manifestações artísticas diversas, tendo sido inspirado no ilustre evento Semaine de Fêtes de Deauville. Foi em função dos contatos e das redes ali geradas e do espírito precursor de Prado que a ideia-projeto de "renovação" nas artes brasileiras iria ganhar força nos anos seguintes, o que desaguaria na organização da Semana de Arte Moderna de 1922. Esse tipo de mecenato artístico ilustrado foi importante para o circuito cultural no contexto paulistano como um todo, mas sobretudo nos momentos que antecederam a emergência do modernismo paulista.

Outro nome que poderia ser trazido à tona, nesse sentido, é o de Olívia Guedes Penteado (1872-1934), apelidada como a "rainha do café", ilustre dama paulista e, também ela, mecenas dos/as modernistas do início do século XX. Segundo Homem (1996) e Waldman (2010), Penteado, que também era filha de aristocratas da lavoura cafeeira (os Barões de Pirapitingui), foi uma personalidade marcante na renovação artística da época, em termos de geração de oportunidades culturais. Pondo-se como irreverente liberal sufragista, lutou pelo voto feminino, ajudando a eleger a primeira mulher para uma constituinte, Carlota Pereira de Queiroz (1892-1982). Olívia foi incentivadora do modernismo, pois consolidou, nos bairros centrais da capital, uma dinâmica de sociabilidade e entretenimento próxima àquela obtida em suas sucessivas permanências em Paris. A exemplo de suas amigas da sociedade francesa, reservava um dia da semana de sua agenda, o "Le Jour de Madame Penteado", como os/as modernistas apelidaram, para receber amigos/as, familiares, artistas e intelectuais da mais alta estirpe em seu casarão, projetado pelo arquiteto Ramos de Azevedo à Rua Conselheiro Nébias, esquina com a Avenida Duque de Caxias, no então elegante e abastado bairro de Campos Elíseos (WALDMAN, 2010). 
Sociogênese possível dos saraus: uma história de rupturas na cultura brasileira Lucas Amaral de Oliveira

Contudo, não foram apenas mecenas endinheirados e ligados/as às grandes plantações de café do Vale do Paraíba que fomentaram o projeto, impulsionaram a ideia e patrocinaram a proposta modernista. Os/as próprios/as artistas, encabeçados por Tarsila do Amaral, Mário de Andrade, Oswald de Andrade e outros/as, responsáveis pela emergência dessa nova estética nas artes, protagonizaram os ensaios de sua manifestação. Foi sua participação ativa em eventos sociais, sua influência em setores da elite progressista e suas reuniões artísticas que geraram as oportunidades culturais, políticas e financeiras necessárias para a emergência do modernismo.

Exemplo é o salão promovido por Tarsila do Amaral, em sua residência na Alameda Barão de Piracicaba, número 44, entre Campos Elíseos e Santa Efigênia. Encontros também eram arranjados por Tarsila e Oswald no ateliê da artista plástica, na Rua Vitória, número 133, na Santa Efigênia. O próprio Mário de Andrade não ficava para trás no que tange ao fomento de redes artísticas e intelectuais via coordenação de salões literários. Em sua casa, na Rua Lopes Chaves, número 546, no bairro da Barra Funda (atual Oficina Cultural Casa Mário de Andrade), o expoente modernista organizava reuniões semanais junto a um seleto grupo de amigos:

Havia a reunião das terças, às noites, na Rua Lopes Chaves. Primeira em data, essa reunião semanal continha exclusivamente artistas e precedeu mesmo a Semana de Arte Moderna. Sob o ponto-de-vista intelectual, foi o mais útil dos salões, se é que se podia chamar salão àquilo. Às vezes doze, até quinze artistas, se reuniam no estúdio acanhado onde se comiam doces tradicionais brasileiros e se bebia um alcoolzinho econômico. A arte moderna era assunto obrigatório (ANDRADE, 1978, p. 239).

Outro exemplo, como lembra Giron (2002), eram as reuniões preparadas por Oswald de Andrade, logo depois de retornar de sua estada europeia e trazer consigo uma cópia do polêmico 
Sociogênese possível dos saraus: uma história de rupturas na cultura brasileira Lucas Amaral de Oliveira

"Manifesto Futurista", de 1909, de Filippo Marinetti (1876-1944), em um apartamento alugado no eruptivo centro paulistano - a despeito da vontade da família -, próximo à Praça do Patriarca. Ele transformou sua residência, estabelecida no terceiro andar da Rua Líbero Badaró, número 67 (prédio que leva, hoje, o número 452, depois de sucessivas alterações), em uma espécie de café-filosófico avant la lettre, preparando saraus com temáticas variadas. Dessas atividades participavam amigos/as de todas as frentes e vertentes: desde Monteiro Lobato, cujas ideias seriam combatidas nos anos posteriores, até Léo Vaz, Menotti del Picchia, Ignácio da Costa Ferreira, Guilherme de Almeida e Miss Ciclone (Maria de Lourdes Castro Pontes). Isso fez do apartamento de Oswald (ou melhor, da garçonnière oswaldiana 6 , ou do "Covil da Rua Líbero", como apelidado pelo escritor), que recebeu as atividades literárias entre 1917 e 1918, um dos berços do modernismo paulista - aliás, foi ali que ele forjou o personagem João Miramar e começou a escrever Memórias Sentimentais de João Miramar, que seria publicado em 1924.

Outro evento central dos primeiros momentos do modernismo em São Paulo foi a Exposição de Arte Moderna de Anita Malfatti (de 12 de dezembro de 1917 a 11 de janeiro de 1918), que ocorreu em um casarão da Rua Líbero Badaró, número 111, onde a artista expôs 53 trabalhos inéditos, muitos deles de aspecto expressionista. Foi marcante especialmente porque, a partir desses encontros, aflorou um conflito bastante animado entre os/as que, cada vez mais, saíam em defesa de uma "revolução" nas artes brasileiras e os/as que ignoravam as qualidades do movimento que emergia, como Monteiro Lobato, por exemplo, que saiu em ataque a Anita n'O Estado de S. Paulo, em 20 de dezembro de 1917, com o texto "A propósito da exposição de Anita Malfatti" - republicado, em 1919, como "Paranoia ou mistificação?" (LOBATO, 1959, p. 61). A desaprovação conservadora de Lobato à liberdade de composição

\footnotetext{
6 Garçonnières eram apartamentos que homens alugavam, no centro de São Paulo, para encontros amorosos e promoção de atividades culturais. Sobre isso, cf. a reportagem de Luís Antônio Giron para a Folha de S. Paulo, em dezembro de 2015 : goo. gl/AiEU2B. Acesso: 22/01/2018. No texto, o jornalista relata a redescoberta desse espaço fundamental para o modernismo, traçando, paralelamente, a abusiva relação de Oswald de Andrade com a normalista Maria de Lourdes Pontes (1900-1919), que acabou falecendo precocemente em razão de um aborto.
} 
Sociogênese possível dos saraus: uma história de rupturas na cultura brasileira Lucas Amaral de Oliveira

e experimentação da pintora paulistana fez com que vários/as integrantes do movimento respondessem à crítica, defendendo Anita e sua arte e consentindo cada vez mais na necessidade de irrupções artísticas.

Foi também em 1918 que o círculo modernista deu as boasvindas a Rubens Borba de Moraes e Sergio Milliet, de volta de suas estadias na Europa, depois de um período de bolsa de formação artística, portando novidades estéticas que iriam agregar valor estético à já agitada atmosfera modernista que se espraiava na cidade. Em salões, exposições e círculos culturais mais restritos e arrojados de São Paulo, vivia-se, nesses anos imediatamente anteriores à consolidação formal do projeto modernista, com a realização da Semana de 1922, ares vanguardistas influenciados por ventos europeus (ou, mais designadamente, franceses), mas antropofagicamente adaptados às ânsias de uma metrópole em plena metamorfose, instigada por um grupo de intelectuais e artistas bastante propositivos/as e controversos/as para a época.

Vale notar que, em termos mais contextuais, as duas primeiras décadas do século XX marcaram, em São Paulo, um espantoso crescimento demográfico, ocasionado por um rápido processo de urbanização e industrialização, sobretudo em decorrência da expansão da economia cafeeira e dos grandes fluxos migratórios (SEVCENKO, 2003). Paralelamente, pairava uma sensação de otimismo com a entrada do Brasil em uma suposta modernidade política, cultural e econômica, ainda que periférica, bem como com o início da industrialização, o advento da República e, como lembra Sevcenko (2003), com a difusão de propostas intelectuais dignas de uma Belle Époque - utilitarismo, liberalismo, positivismo, humanismo, vanguardismo. Ou seja, tratava-se de um caldeirão de confiança e bem-estar em setores da elite, assegurado pela entrada de capitais internacionais, de migrantes europeus e de novas ideias que sugeriam mudanças ${ }^{7}$.

\footnotetext{
7 Há textos da sociologia da arte e da cultura analisando o meio intelectual nos anos iniciais do século XX e seu impacto na Semana e Arte Moderna de 1922. Botelho (2011; 2012), Carvalho (1988), Hardman (1996), Passiani (2007), Schwarz (2004), Sevcenko (2003) e Teixeira (2014), por exemplo, redesenham o período, mostrando a importância do ideal modernista para a construção de um campo artístico em busca de certa autonomia em relação às vanguardas europeias e explicitando a relevância de fatos, polêmicas, salões, manifestos e críticas para a criação de uma vida intelectual no país (ARRUDA, 2011; LAFETÁ, 2000; SCHWARTZ, 1995; SIMIONI, 2013).
} 
Sociogênese possível dos saraus: uma história de rupturas na cultura brasileira Lucas Amaral de Oliveira

Os saraus e os salões, como atividade artística preferida dessa elite, em meio ao torvelinho de mudanças e de novas propostas, constituíam um microcosmo sociocultural que evidenciava, de acordo com Gustavo Sorá (2010, p. 66), uma sociedade no vértice de sua formação enquanto nação, em busca de uma identidade que a unificasse artística e culturalmente. Essa sociedade foi caracterizada por uma nova formatação das posições sociais anteriormente dispostas na estrutura de classes no Brasil, em termos dos indivíduos que vivenciavam a passagem de um passado agrícola e patriarcal para o mundo urbano de ofícios e serviços diferenciados, sustentado por novas alianças e disputas de poder econômico e político. Em especial, o decênio de 1920, em São Paulo, consolidou anseios latentes de renovação, não só política e econômica, mas, principalmente, artística e literária; foi nessa década que medidas renovadoras em todos os campos da vida cultural manifestaram uma vitalidade nunca antes vista, que foi a sementeira de profundas modificações no futuro próximo. Segundo a equação de Candido (1999, p. 77):

Os intelectuais, em geral, os artistas e escritores, em particular, passaram a encarar a realidade com olhar mais crítico, denunciando a insuficiência de uma visão oficial que procurava mostrar o país como extensão do modo de ser, de viver e de pensar das suas elites tradicionais. As presenças do negro, do mestiço, do proletário, do campesino espoliado, do imigrante se fizeram sentir com força graças à mudança social e ao advento de novas relações de trabalho, no quadro da urbanização e da indústria em desenvolvimento. Os modernistas foram sensíveis a esse Brasil novo, procurando exprimir a sua variedade por diversas maneiras.

O que Candido sugere é que o surto industrial dos anos de guerra, os fluxos migratórios e a urbanização permitiram que São Paulo passasse a impressão de ser um local cosmopolita e comparável aos grandes centros europeus. E, aqui, fica evidente 
Sociogênese possível dos saraus: uma história de rupturas na cultura brasileira Lucas Amaral de Oliveira

a relação de equivalência entre a atividade artística gerada no período e o momento socioeconômico, bem como a relação entre uma intelectualidade artística e esse novo agrupamento social ao qual pertenciam os barões do café. Ainda que se tratasse de um período de inédita industrialização, segundo Lafetá (2000, p. 23), o projeto modernista da década de 1920 não nasceu com o patrocínio dos novos capitães de indústria, mas da "parte mais refinada da burguesia rural, os detentores das grandes fortunas de café que acolhem, estimulam e protegem os escritores da nova corrente".

O fato que gostaria de extrair dessa discussão toda é que, na ausência de instituições culturais propriamente consolidadas em São Paulo da virada do século XIX para o XX - cidade que ainda bebericava das águas de um progresso que, então, tocava os pés e as mãos apenas de alguns setores sociais da burguesia -, e em meio à carência de uma esfera pública apadrinhadora de ambientes de expressão, produção, difusão e consumo artísticos, importantes personalidades do mecenato paulista (Dona Veridiana, Freitas Valle, Paulo Prado e Olívia Guedes Penteado), ligados/as à uma rica elite cafeeira em ascensão, destacaram-se como gatekeepers, responsáveis por abrir portas a novas tendências e estilos para as artes nacionais. Isso, porque eles/as foram mediadores/ as fundamentais que lograram unir diferentes esferas das elites econômicas e artísticas no país a um circuito favorável para o surgimento e a consolidação de novas ideias, projetos e experimentalismos, ficando incumbidos/as de possibilitar espaços de encontros e de efetivar instâncias de consagração, distribuindo prestígio entre artistas, tecendo conexões necessárias para financiamentos e promovendo o "ideário moderno" na produção artística.

Nesse sentido, é possível afirmar que houve uma relação direta entre o apogeu dos salões artísticos paulistanos, entre 0 final do século XIX e o início do XX - que eram, no frigir dos ovos, os grandes redutos das vanguardas nacionais -, a prosperidade de palacetes de uma alta burguesia agrário-industrial em expansão 
Sociogênese possível dos saraus: uma história de rupturas na cultura brasileira Lucas Amaral de Oliveira

e que, então, aderia às novidades da vida urbana, a eclosão de movimentos renovadores no interior do campo artístico nacional e o forte ciclo de industrialização por que passava o Estado de São Paulo, impulsionada, em especial, pela economia do café e por consequentes processos de urbanização e desenvolvimento. Esses salões literários, arranjados em torno de políticos, empresários/as, escritores/as, proprietários/as de terras, o mecenato progressista e toda sorte de artistas, a despeito das contradições que podem sugerir a diversidade de seus arranjos e de suas relações, acabaram sendo espaços provocadores de um espírito cosmopolita que fundia a absorção de novas ideias, muitas delas importadas do continente europeu, com a reiteração da cultural nacional, retraduzindo-as antropofagicamente, processo que ratificou desejos de mudança nas artes. Isso culminou na consolidação do movimento modernista e no preparo da Semana de Arte de 1922 - manifestação ocorrida durante as comemorações do centenário da independência, outro marco importante do período.

Até meados de 1930, os mais significativos focos de vida cultural da cidade de São Paulo se encontravam justamente nesses salões de pequenos círculos da elite paulistana. O mecenato artístico, os recitais arranjados por algumas famílias tradicionais ligadas à aristocracia cafeeira, juntamente com as festas, os encontros e as exposições protagonizadas pelos/as próprios/as modernistas, desempenharam papel fundamental no processo de modernização artística de São Paulo, o que concedeu à cidade traços de uma Belle Époque cultural, social, urbana e política (NEVES, 2011). Foi por intermédio dessas redes que pintores/as, músicos/as, escultores/ as, escritores/as e mecenas lograram angariar recursos materiais e simbólicos suficientes para concretizar aquilo que Antonio Candido (2006) definiu, certa feita, como um momento crucial no processo de constituição da cultura brasileira.

Isso pode sugerir um vínculo entre posição social, economia do gosto e produção estética. Basta lembrar que os salões e a movimentação literária desenvolvidos nos palacetes de São Paulo, no início do século XX, foram muito benquistos pela elite 
Sociogênese possível dos saraus: uma história de rupturas na cultura brasileira Lucas Amaral de Oliveira

cafeeira em ascensão, que os financiava e os encorajava a novos horizontes nas artes. O modernismo, naquele contexto, cavou um terreno propício para experimentações e rupturas dentro do enquadramento sociopolítico disponível. Contudo, ainda que tal geração tenha se contraposto a certos cânones, ideologias e convenções estéticas importadas da Europa, é preciso salientar sua relação licenciosa com os poderes instituídos da época, bem como sua afinidade intelectual com uma burguesia intelectualizada e urbana nascente, o que confinou o movimento a um espaço restrito de atuação e produção. Afinal, não se pode esquecer que, ainda que de maneira irônica e espirituosa, um dos grandes nomes da chamada "Geração de 1920", Oswald de Andrade, costumava qualificar a si como o grande "palhaço da burguesia" (CANDIDO, 2002, p. 240).

\section{Considerações finais}

Este artigo não teve como objetivo traçar uma comparação estético-cultural entre o movimento modernista e o movimento da literatura marginal contemporânea. Tampouco pretendeu sobrepor uma lógica interpretativa de hoje para outros tempos e outros/as agentes - tenho ciência de que os movimentos são tempestivos. A intenção foi utilizar as narrativas de origem dos poetas Binho e Sérgio Vaz como provocações sociológicas e ignições reflexivas que ajudassem na construção de uma hipótese sobre uma sociogênese possível do termo e da prática dos saraus literários, retomando a ideia e a história desse tipo de prática cultural nos salões europeus e verificando como se deu a sua transposição para a rotina brasileira, mediada por mecenas e financiada pela aristocracia cafeeira. Esses salões mostraram-se focos desenvolvedores de um dos maiores movimentos culturais a história do país, o modernismo paulista, tendo desempenhado papel importante, também, nos processos de legitimação e consagração de objetos artísticos produzidos por integrantes desse movimento. 
Sociogênese possível dos saraus: uma história de rupturas na cultura brasileira Lucas Amaral de Oliveira

Embora tenha se tratado de uma arte disruptiva para os paradigmas vigentes, ao mesmo tempo o modernismo paulista mostrou-se uma arte ensaiada por uma elite burguesa, branca, exclusivista e com certas liberdades possibilitadas pela posição social de seus/suas integrantes. Ainda que não se possa falar de um grupo homogêneo, muitos/as de seus/suas integrantes eram provenientes de uma elite que habitava o então nobre centro paulistano e que havia completado a sua formação intelectual e artística na Europa, usufruindo do arrimo de mecenas. Esse arranjo fez com que se avizinhassem de espaços mais privilegiados de produção, difusão e consumo de objetos artísticos, bem como de movimentos e instâncias que apoiavam experimentalismos.

As narrativas de Binho e Vaz são interessantes não pelo grau de precisão de sua factualidade, mas porque motiva as ciências sociais a revisitar parte da história cultural do país a partir de uma leitura desinstitucionalizada, a contrapelo, ou seja, que considere as estruturas e as estratégias que foram operacionalizadas no decorrer da história para valorizar certo tipo de produção artística e desconsiderar outras que fugiam da economia do gosto de certa elite urbana. Talvez um dos maiores legados do termo e da prática dos salões de antes para os saraus literários das periferias de hoje seja o fato de que eles seguem sendo instâncias importantes de produção, fruição, circulação, consumo e legitimação de bens simbólicos. Espero que este texto sirva de estímulo para que pesquisas avancem nesse caminho analítico: traçar paralelos entre os saraus que animam as margens urbanas de cidades brasileiras e os salões literários do passado, em termos de geração e distribuição de oportunidades culturais e incentivo à sociabilidade artística.

De um lado, é preciso perceber como ambos os modelos foram capazes de fomentar discussões sobre novos experimentalismos estéticos no campo literário nacional de seus respectivos períodos, funcionando como espaços privilegiados para rupturas artísticas e para a emergência e consagração de muitos/as artistas. Mas, por outro, as diferenças devem ser sopesadas, porque são 
Sociogênese possível dos saraus: uma história de rupturas na cultura brasileira Lucas Amaral de Oliveira

também significativas, tanto na forma de organização artística, como nas oportunidades geradas, tanto na proposta estética, quanto no público visado para consumir os bens simbólicos ali produzidos. Essas diferenças, inclusive, já estavam expostas nas narrativas trazidas por Binho e Vaz. Em todo processo em que há deslocamento de um termo (e de uma prática) para outro universo e tempo, há inovações e diferenciações que devem ser demarcadas (TENNINA, 2013). Os espaços são outros, assim como são outras as dinâmicas, as preocupações, a própria maneira de arranjar a sociabilidade, os/as participantes, suas origens socioeconômicas etc. Diferentemente dos salões realizados pelos mecenas do início do século $X X$, os saraus periféricos vêm operando, hoje, como verdadeiros "caldeirões culturais nas margens geográficas e simbólicas das grandes cidades brasileiras", como atestou Binho, em entrevista de abril de 2014; isto é, enquanto lugares de valorização da cidadania cultural nas periferias, de seus bens simbólicos, e também como componentes de identificação coletiva entre os/as membros, organizadores/as, autores/as, intervenientes, simpatizantes.

Portanto, se há uma apropriação disruptiva da tradição ou uma reinvenção antropofágica do termo sarau para dar nome à prática oralizada e performatizada do movimento da literatura marginal contemporânea, é preciso atentar para a condição interseccionalmente periférica à qual estão submetidos os saraus e seus/suas agentes: de classe, raça, status, localização geográfica e oportunidades de criação. Essa condição periférica assinala a maior diferença de posições de "quem fala" e "de onde se fala" (geográfica, simbólica e epistemicamente) nos fenômenos de antes e de agora.

\section{Referências}

ANDRADE, Mário de. O Movimento Modernista. In: Aspectos da Literatura Brasileira. São Paulo, Livraria Martins Editora, 1978, p. 231-258. 
Sociogênese possível dos saraus: uma história de rupturas na cultura brasileira Lucas Amaral de Oliveira

ARRUDA, Maria Arminda do Nascimento. Metrópole e Cultura. Bauru, Edusc, 2001.

BALBINO, Jéssica. Pelas Margens: vozes femininas na literatura periférica. Campinas, 2016. Dissertação (Mestrado em Divulgação Científica e Cultural) - Universidade Estadual de Campinas, Campinas, 2016.

BASÍLIO, Ana Luiza; MOREIRA, Jéssica. Saraus das cidades- sede colaboram com a mobilização comunitária. Porta Aprendiz, 23 de janeiro de 2014. Disponível em: goo.gl/iueRys.Acesso em: 29 dez 2015.

BERTELLI, Giordano; FELTRAN, Gabriel (Orgs.) Vozes à Margem: periferias, estética e política. São Carlos: EDUFSCar/CEM, 2017. BOTELHO, André. A Pequena história da literatura Brasileira: provocação ao modernismo. Tempo Social, São Paulo, v. 23, n. 2, p. 135-161, novembro de 2011.

BOTELHO, André. De olho em Mário de Andrade: uma descoberta intelectual e sentimental do Brasil. São Paulo, Claroenigma, 2012.

BOURDIEU, Pierre. As Regras da Arte. São Paulo, Companhia das Letras, 1996.

BOURDIEU, Pierre. Pierre Bourdieu avec Löic Wacquant: réponses. Paris, Seuil, 1992.

CAMARGOS, Márcia. Villa Kyrial: crônica da Belle Époque paulistana. São Paulo, Senac, 2000.

CANDIDO, Antonio. 0 discurso e a cidade. São Paulo, Duas Cidades, 1993.

CANDIDO, Antonio. Iniciação à literatura brasileira. São Paulo, Humanitas, 1999.

CANDIDO, Antonio. Literatura e sociedade. Rio de Janeiro, Ouro Sobre Azul, 2006. 
Sociogênese possível dos saraus: uma história de rupturas na cultura brasileira Lucas Amaral de Oliveira

CARVALHO, José Murilo de. Aspectos históricos do pré-modernismo brasileiro. In: Sobre o pré-modernismo. Rio de Janeiro, Fundação Casa de Rui Barbosa, 1988, p. 13-21.

CASANOVA, Pascale. A República Mundial das Letras. São Paulo, Estação Liberdade, 2002.

CLEMENTE, Claudelir Correa; SILVA, José Carlos Gomes da. Dos quilombos à periferia: reflexões sobre territorialidades e sociabilidades negras urbanas na contemporaneidade. Crítica \& Sociedade, Uberlândia, v. 4, n. 1, p. 86-106, 2014.

COSTA, Bianca Alves. Poesia e lugar: movimentos literários como possibilidades de democratização do espaço urbano. São Paulo, 2011. Dissertação (Mestrado em Geografia), Pontifícia Universidade Católica de São Paulo, São Paulo, 2011.

COUTINHO, Fernanda Maria Abreu. Pierre Bourdieu e a gênese do campo literário. Revista de Letras, Fortaleza, v. 1(2), p. 53-59, 2004.

D’AVILA, Luiz Felipe. Dona Veridiana: a trajetória de uma dinastia paulista. São Paulo, A Girafa, 2004.

DANDREY, Patrick (Org.) Dictionaire des lettres françaises: le XVIle siècle. Paris, Fayard, 1996.

DARNTON, Robert. Poesia e polícia: redes de comunicação na Paris do século XVIII. São Paulo, Companhia das Letras, 2014.

DUFOUR-MAÎTRE, Myriam. Les Précieuses: Naissance des femmes de lettres en France au XVIle siècle. Paris, Honoré Champion, 2008.

DOMINGOS, Ricardo Ibrhaim Matos. Mal de Cooperifa: a criação de um arquivo na literatura marginal. Landa, Florianópolis, v. 3, p. 129-142, 2015.

ELIAS, Norbert. O processo civilizador. v. 1, Zahar, Rio de Janeiro, 1994. 
Sociogênese possível dos saraus: uma história de rupturas na cultura brasileira Lucas Amaral de Oliveira

FREYRE, Gilberto. Ingleses no Brasil: aspectos da influência britânica sobre a vida, a paisagem e a cultura do Brasil. Rio de Janeiro, José Olympio, 2003.

GIRON, Luís Antônio. Bruta sacudidela nas artes nacionais! Revista Cult, São Paulo, n. 55, p. 42-49, fevereiro de 2002. Disponível em: bit.ly/2raNBO1. Acesso em: 24 set. 2015.

GUNUSTZMANN, Pricila. Espaços de existência: identidade, poesia e emancipação em um sarau periférico. São Paulo, 2017. 282 f. Tese (Doutorado em Psicologia: Psicologia Social) - Pontifícia Universidade Católica de São Paulo, São Paulo, 2017.

HAPKE, Ingrid; TENNINA, Lucía; SILVA, Mário Augusto Medeiros da; NASCIMENTO, Erica Peçanha do (Orgs.) Polifonias Marginais. Rio de Janeiro, Aeroplano Editora, 2015.

HARDMAN, Francisco Foot. Antigos modernistas. In: NOVAES, Adauto (Org.) Tempo e história. São Paulo, Companhia das Letras, 1996, p. 289-305.

HOFSTADTER, Dan. $\mathbf{O}$ caso de amor com obra de arte. Rio de Janeiro, Record, 1997.

HOMEM, Maria Cecília. O Palacete Paulistano. São Paulo, Martins Fontes, 1996.

JADHAV, Arun Murlidhar. The Sociology of Literature: A Study of Gatekeepers of Literature. Golden Research Thoughts, 3, n. 4, p. 1-4, October 2013.

LAFETÁ, João Luís. 1930: a crítica e o modernismo. São Paulo, Editora 34, 2000.

LEITE, Antonio Eleilson. Mesmo céu, mesmo CEP: produção literária na periferia de São Paulo. 2014. Dissertação (Mestrado em Estudos Culturais) - Escola de Artes, Ciências e Humanidades, Universidade de São Paulo, São Paulo, 2014.

LILTI, Antoine. Les salons d'autrefois: xviie ou xviiie siècle? Les

Cahiers du Centre de Recherches Historiques, 28-29, 2002.

Disponível em: shorturl.at/dILMW. Acesso em: 28 out. 2019. 
Sociogênese possível dos saraus: uma história de rupturas na cultura brasileira Lucas Amaral de Oliveira

LOBATO, Monteiro. Paranóia ou Mistificação? A propósito da Exposição Malfatti. In: Ideias de Jeca Tatu. São Paulo, Brasiliense, 1959, p. 59-65.

MACEDO, Joaquim Manuel de. A moreninha. São Paulo, Ática, 2002.

MAINGUENEAU, Dominique. O contexto da obra literária. São Paulo, Martins Fontes, 1995.

MARCHAL, Roger (Org.) Vie des salons et activités littéraires: de Marguerite de Valois à Mmede Staël. Nancy, Presses Universitaires de Nancy, 2001.

MATTA, Carmen da. Rio de Janeiro, solo configurador da literatura nacional. Revista Rio de Janeiro, UERJ, Rio de Janeiro, v. 10, p. 259-277, 2003.

NASCIMENTO, Érica Peçanha do. É tudo nosso! Produção cultural na periferia paulistana. São Paulo, 2011. Tese (Doutorado em Antropologia Social) - Faculdade de Filosofia, Letras e Ciências Humanas, Universidade de São Paulo, São Paulo, 2011.

NASCIMENTO, Erica Peçanha do. Vozes marginais na literatura. Rio de Janeiro, Aeroplano/ Fapesp, 2009.

NEVES, Juliana. São Paulo no segundo pós-guerra: imprensa, mercado editorial e o campo da cultura na cidade. Revista Brasileira de Ciências Sociais, v. 26, p. 119-132, 2011.

OLIVEIRA, Lucas Amaral de. Experiências estéticas em movimento: produção literária nas periferias paulistanas. São Paulo, 2018. Tese (Doutorado em Sociologia) - Universidade de São Paulo, São Paulo, 2018a.

OLIVEIRA, Lucas Amaral de. Experiência literária e experiência urbana: notas sobre a literatura marginal. Veredas, Lisboa, n. 27, p. 24-46, 2018b.

PARDUE, Derek; OLIVEIRA, Lucas Amaral de. City as Mobility: The Contribution of Brazilian Saraus to Urban Theory. Vibrant, Florianópolis, v. 14, n. 3, p. 282-305, 2018. 
Sociogênese possível dos saraus: uma história de rupturas na cultura brasileira Lucas Amaral de Oliveira

PASSIANI, Enio. Páginas recolhidas: cultura impressa, modernismo e protocolos de leitura em São Paulo (1922-1928). São Paulo, 2007. Tese (Doutorado em Sociologia) - Universidade de São Paulo, São Paulo, 2007.

PINHO, Wanderley. Salões e damas do Segundo Reinado. São Paulo, Gumercindo Rocha Dorea, 2004.

REYES, Alejandro. Vozes do Porão: a literatura periférica/marginal do Brasil. Rio de Janeiro, Aeroplano \& Tramas Urbanas, 2013.

SÁ DE ARAÚJO, Jander. A Poética do Sarau em A Moreninha: liturgia e semiose. Rio de Janeiro, 2012. Dissertação (Mestrado em Letras). Universidade Federal Fluminense, Rio de Janeiro, 2012.

SALIBA, Elias. Nos tempos da Villa Kyrial. Revista USP, São Paulo, n. 50, p. 303-307, 2001.

SALOM, Julio Souto. Combater a subcidadania disputando o jogo literário: uma contribuição ao estudo da literatura marginal-periférica. Porto Alegre, 2014. Dissertação (Mestrado em Sociologia), Universidade Federal do Rio Grande do Sul, Porto Alegre, 2014.

SANTIAGO, Silvano. A permanência do discurso da tradição no modernismo. In: Nas malhas da letra. São Paulo: Companhia das Letras, 1989, p. 94-123.

SCHWARTZ, Jorge. Vanguardas latino-americanas: polêmicas, manifestos e textos críticos. São Paulo, Iluminuras \& EDUSP, 1995.

SCHWARZ, Roberto. Crítica de intervenção. Rodapé: Crítica de Literatura Brasileira Contemporânea, n. 3. São Paulo, Nankin, 2004, p. 13-33.

SCHWARZ, Roberto. Ideias fora do lugar. In: Cultura e Política. São Paulo, Paz \& Terra, 2009, p. 59-83. 
Sociogênese possível dos saraus: uma história de rupturas na cultura brasileira Lucas Amaral de Oliveira

SCHWARZ, Roberto. Pressupostos, salvo engano, de Dialética da malandragem. In: Que horas são? São Paulo, Companhia das Letras, 1987, p. 129-155.

SEVCENKO, Nicolau. Literatura como missão. São Paulo, Companhia das Letras, 2003.

SILVA, Simone. As rodas literárias nas décadas de 1920-30: troca e reciprocidade no mundo do livro. Rio de Janeiro, 2004. Dissertação (Mestrado em Antropologia), Universidade Federal do Rio de Janeiro, Rio de Janeiro, 2004.

SIMIONI, Ana Paula C. Modernismo brasileiro: entre a consagração e a contestação. Perspective: actualité en histoire de l'art, Paris, n. 2, p. 1-17, 2013.

SORÁ, Gustavo. Brasilianas: José Olympio e a gênese do mercado editorial brasileiro. São Paulo, EDUSP, 2010.

TEIXEIRA, Ana Lúcia. Nacionalismo em verso e prosa: a modernidade almejada no contexto do modernismo paulista. In: EL FAR, Alessandra; BARBOSA, Andréa; AMADEO, Javier (Orgs.) Ciências Sociais em diálogo - Vol. II. São Paulo, FAP-Unifesp, 2014, p. 239-266.

TENNINA, Lucía. Cuidado com os poetas! Literatura e periferia na cidade de São Paulo. Porto Alegre, Zouk, 2017.

TENNINA, Lucía. Saraus das periferias de São Paulo: poesia entre tragos, silêncios e aplausos. Estudos de Literatura Brasileira Contemporânea, Brasília, n. 42, p. 11-28, 2013.

VAZ, Sérgio. Cooperifa: Antropofagia Periférica. Rio de Janeiro, Aeroplano, 2008.

WALDMAN, Thais. À "frente" da Semana de Arte Moderna: a presença de Graça Aranha e Paulo Prado. Estudos Históricos, Rio de Janeiro, v. 23, n. 45, p. 71-94, 2010.

WALDMAN, Thais. Moderno Bandeirante: Paulo Prado entre espaços e tradições. São Paulo, Alameda Casa Editorial, 2014. 